\title{
An analysis on the relationship between land subsidence and floods at the Kujukuri Plain in Chiba Prefecture, Japan
}

\author{
Y. Ito ${ }^{1}$, H. Chen ${ }^{2}$, M. Sawamukai ${ }^{3}$, T. Su ${ }^{1}$, and T. Tokunaga ${ }^{1}$ \\ ${ }^{1}$ Graduate School of Frontier Sciences, The University of Tokyo, 5-1-5 Kashiwanoha, Kashiwa City, \\ Chiba, 277-8563, Japan \\ ${ }^{2}$ School of Environmental Science and Engineering, Zhejiang Gongshang University, Hangzhou, 310018, China \\ ${ }^{3}$ VisionTech Inc., Tsukuba City, Ibaraki, 305-0045, Japan \\ Correspondence to: Y. Ito (yu_ito@geoenv.k.u-tokyo.ac.jp)
}

Published: 12 November 2015

\begin{abstract}
Surface environments at the Kujukuri Plain in Chiba Prefecture, Japan, in 1970, 2004, and 2013, were analyzed and compared to discuss the possible impact of land subsidence on the occurrence of floods. The study area has been suffered from land subsidence due to ground deformation from paleo-earthquakes, tectonic activities, and human-induced subsidence by groundwater exploitation. Meteorological data, geomorphological data including DEM obtained from the airborne laser scanning (1-m spatial resolution), leveling data, and the result of our assessment map (Chen et al., 2015) were used in this study. Clear relationship between floods and land subsidence was not recognized, while geomorphological setting, urbanization, and change of precipitation pattern were found to contribute to the floods. The flood prone-area is distributed on the characteristic geomorphological setting such as floodplain and back swamp. It was revealed that the urban area has been expanded on these geomorphological setting in recent years. The frequency of hourly precipitation was also shown to be increased in the past ca. 40 years, and this could induce rapid freshet and overflow of small- and medium-sized rivers and sewerage lines. The distribution of depression areas was increased from 2004 to 2013. This change could be associated with the ground deformation after the Tohoku earthquake $\left(M_{\mathrm{w}}=9.0\right)$ in 2011 .
\end{abstract}

\section{Introduction}

Land subsidence causes several problems which include changes in elevation, groundwater salinization in coastal area, structural damage, and increase in the potential for flooding (Galloway et al., 1999; Ng et al., 2015). Land subsidence has occurred at many areas in Japan. The Kujukuri Plain, Chiba Prefecture, Japan (Fig. 1), is one of the areas experiencing land subsidence which is caused by ground deformation from paleo-earthquakes, tectonic activities, and human-induced subsidence by groundwater abstraction. The maximum value of accumulated subsidence is ca. $1 \mathrm{~m}$ at the Mobara City during the period from 1969 to 2014 (Chiba Prefecture, 2014). This coastal area is relatively flat with its elevation lower than $10 \mathrm{~m}$. The lowland consists of three main landforms (Fig. 1) (Moriwaki, 1979): (1) beach ridge;
(2) sand dune; and (3) back swamp and flood plain. Therefore, the impact of land subsidence on the surface environment has been concerned in this area; one of its effects may include the increase of the frequency of flooding. In the south Kujukuri plain area, floods have repeatedly occurred in the past. There were at least 16 large flood events in this area during the period between 1970 and 2013. The frequency of large flood events had relatively low before 1970. Figure 2 shows the flood inundation areas of the 1 July 1970, 8-11 October 2004, 16 October 2013.

In this study, we analyzed and compared the factors of the floods in 1970, 2004, and 2013 by using GIS to assess the possible impact of land subsidence on the occurrence of floods. The three periods were selected because of the following reasons; 1970 is after huge land modification, 2004 is 


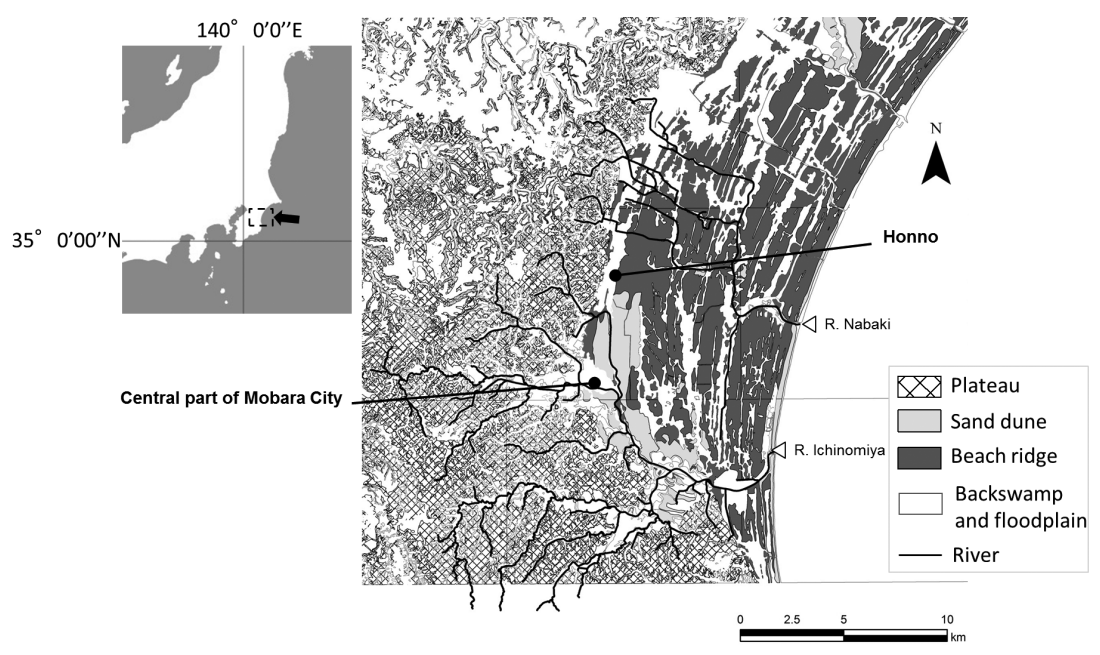

Figure 1. Geomorphological map of the Kujukuri Plain. Study area is Nabaki and Ichinomiya Rivers watershed.
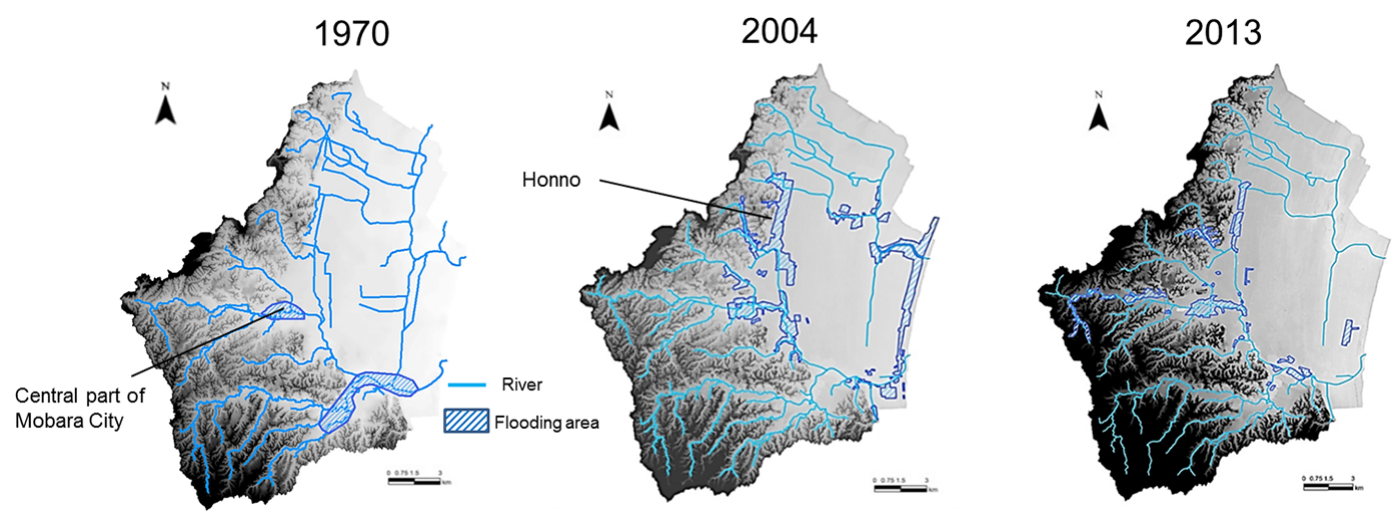

Figure 2. Flood inundation area in 1970, 2004, and 2013. Flood area was digitalized from the flood report of Chiba prefecture (1971, 2005, and 2015).

prior to the 2011 off the Pacific coast of Tohoku Earthquake $\left(M_{\mathrm{W}}=9.0\right)$, and 2013 is after the earthquake.

\section{Analyses of the factors related to floods}

Three major factors which were related to floods were analyzed - climatic, geomorphologic, and human factors.

\subsection{Climatic factor}

The intensity and frequency of precipitation may affect the frequency and magnitude of floods (Fitzpatrick et al., 1999). Spatial distribution of the Radar/raingauge-Analyzed precipitation data obtained from Japan Meteorological Agency in 2004 and 2013, indicate that the spatial rainfall pattern could affect the flooding area. The flooding area in 2004 was mainly recognized in coastal area and the central part of the Mobara city (Fig. 2) due to high intensity rainfalls in the lower reach of the Nabaki River and the higher tidal level. In 2013, the upper reaches of the Ichinomiya River and the central part of the Mobara city were flooded (Fig. 2) because the rainfall was concentrated in the upper reaches of the Ichinomiya River. The lower reaches were not flooded because the tidal level was low and the rainfall was not strong. The results of our assessment maps in 2004 and 2013 (Chen et al., 2015) also suggested that the flood areas were affected by the spatial rainfall pattern.

Frequency of hourly precipitation of more than $50 \mathrm{~mm} \mathrm{~h}^{-1}$ is shown to be increased during the past ca. 40 years within the watersheds, and this could induce rapid freshet and overflow of small- and medium-sied rivers and sewerage lines.

\subsection{Geomorphological factor}

Alluvial and coastal lowlands have a potential floods risk (Umitsu, 2012). Flood inundation area is mainly recognized on floodplains, back swamp, Holocene terrace, and reclaimed land in three periods (Fig. 3 and Table 1). Coastal plain and beach ridges are also flooded. 

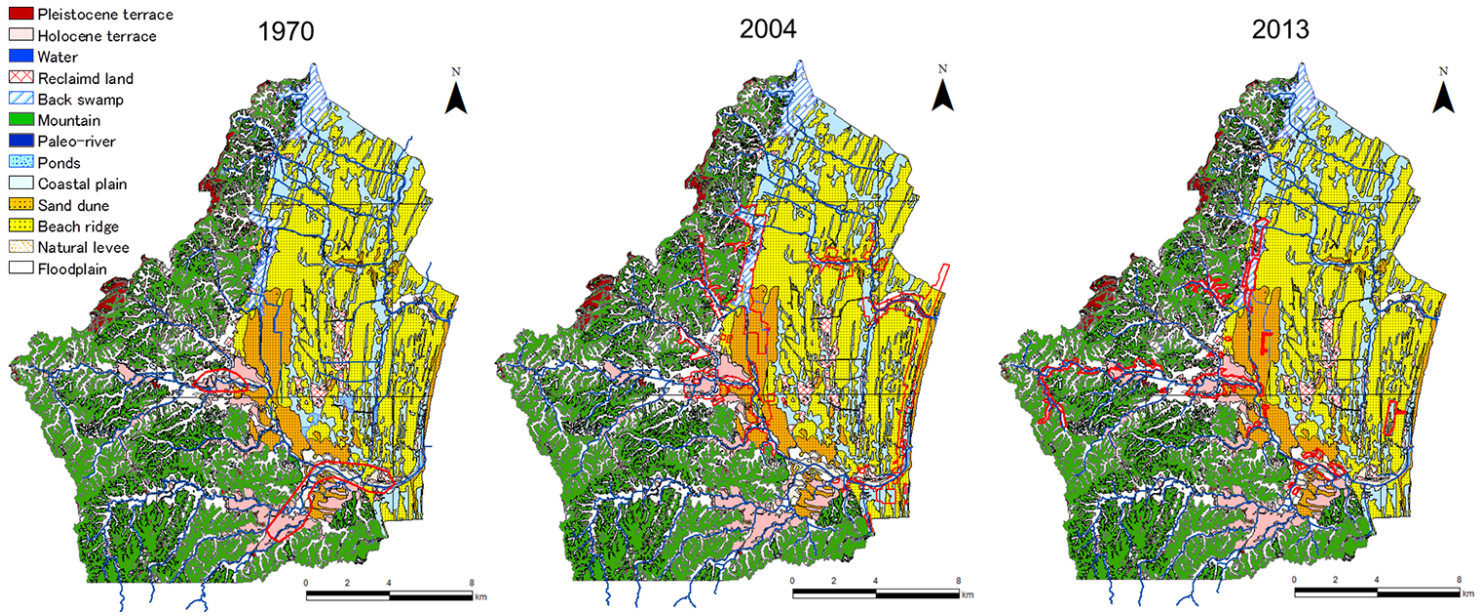

Figure 3. Geomorphological classification map in 1970, 2004, and 2013 based on land condition map (1 / 25 000) of Geospatial Information Authority of Japan. Red line indicates flood inundation area.

Table 1. Ratio of flood inundation area by geomorphological condition.

\begin{tabular}{lrrr}
\hline $\begin{array}{l}\text { Geomorphological } \\
\text { classification }\end{array}$ & 1970 & 2004 & 2013 \\
\hline Holocene terrace & $29.01 \%$ & $5.74 \%$ & $13.74 \%$ \\
Flood plain & $23.06 \%$ & $16.42 \%$ & $31.74 \%$ \\
Natural levee & $17.34 \%$ & $1.88 \%$ & $4.99 \%$ \\
Beach ridge & $6.92 \%$ & $25.94 \%$ & $5.07 \%$ \\
Reclaimed land & $7.57 \%$ & $9.19 \%$ & $10.22 \%$ \\
Water & $5.60 \%$ & $2.88 \%$ & $5.11 \%$ \\
Sand dune & $4.15 \%$ & $11.66 \%$ & $5.00 \%$ \\
Ponds & $2.40 \%$ & $0.82 \%$ & $0.52 \%$ \\
Coastal plain & $2.29 \%$ & $11.91 \%$ & $3.95 \%$ \\
Back swamp & - & $12.69 \%$ & $14.82 \%$ \\
Mountain & $0.94 \%$ & $0.41 \%$ & $3.27 \%$ \\
Paleo-river & $0.62 \%$ & $0.36 \%$ & $1.39 \%$ \\
Pleistocene terrace & $0.09 \%$ & - & - \\
Others & - & $0.11 \%$ & $0.17 \%$ \\
\hline
\end{tabular}

In particular, in the central part of the Mobara City which is flood-prone area (Fig. 2), the floods occur on the flood plains surrounded by slightly highland (relative elevation: $+1-2 \mathrm{~m}$ ) such as natural levee and Holocene terraces. Honno, are the flood-prone area, is also situated on back swamp and is often flooded even with a light rainfall due to the area is surrounded by sandbars or beach ridges. Therefore, the flood-prone area may depend heavily on the characteristics of the geomorphological setting.

Local topographic depressions were extracted from the 1$\mathrm{m}$ mesh resolution DEM. The results showed that the distribution of depressions was mostly unchanged from 1970 to 2004, however, was changed in 2013, particularly in the Nabaki River mouth and its surroundings (Fig. 4). This
Table 2. Impermeable area ratios in each land cover.

\begin{tabular}{lccc}
\hline Land cover classification & 1970 & 2004 & 2013 \\
\hline Urban & 0.20 & 0.30 & 0.30 \\
Building & 0.14 & 0.25 & 0.21 \\
Farmland & 0.12 & 0.18 & 0.11 \\
Paddy & 0.09 & 0.09 & 0.10 \\
Sands & 0.12 & 0.09 & 0.07 \\
Grassland & 0.07 & 0.09 & 0.10 \\
Forest & 0.07 & 0.07 & 0.08 \\
Water & 0.08 & 0 & 0.03 \\
Bareland & 0.15 & - & - \\
\hline
\end{tabular}

change might be the influence of the ground deformation after the $M_{\mathrm{w}}=9.0$ earthquake in 2011 .

\subsection{Human factor}

Urban development of the Mobara city and its surroundings was quite rapid during 1970-2013 (Fig. 5). The ratio of urban and building estate areas were $15.4 \%$ in 2004 and $17.4 \%$ in 2013, respectively, while $9.5 \%$ in 1970 . Farm lands and paddy areas were decreased during the period from 1970 to 2013. Impermeable area ratios in each land cover also change with land cover changing (Table 2). The area ratio of urban and building have increased from 0.20 and 0.14 in 1970 to 0.30 and $0.21-0.25$ in 2004-2013, respectively.

The Urban areas have spread into lowland area such as flood plains and back swamps since 1970. This is clearly reflected in the relationship between the urbanization area and the landforms. The results of the analysis on the relationship between built-up area and the geomorphological changes (Fig. 6) indicate that the built-up area have expanded on vulnerable landforms with respect to floods, i.e., flood 

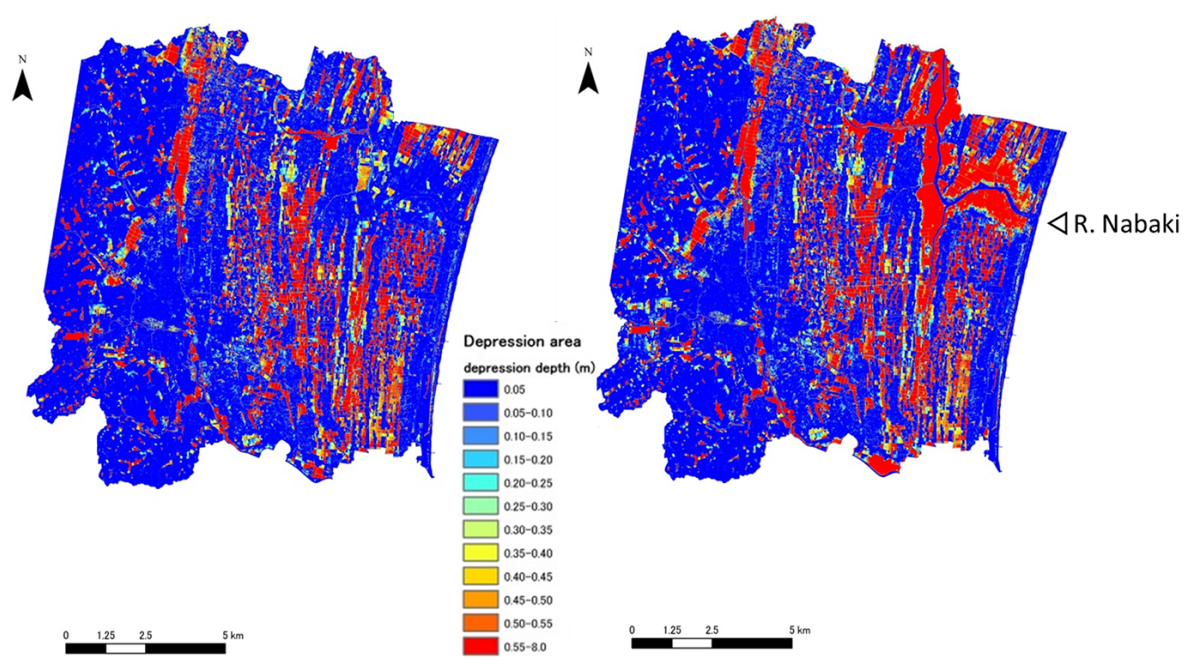

Figure 4. Distribution of depressions in 2004 and 2013. 1-m mesh digital elevation model obtained from the airborne laser scanning survey was used for the analysis.
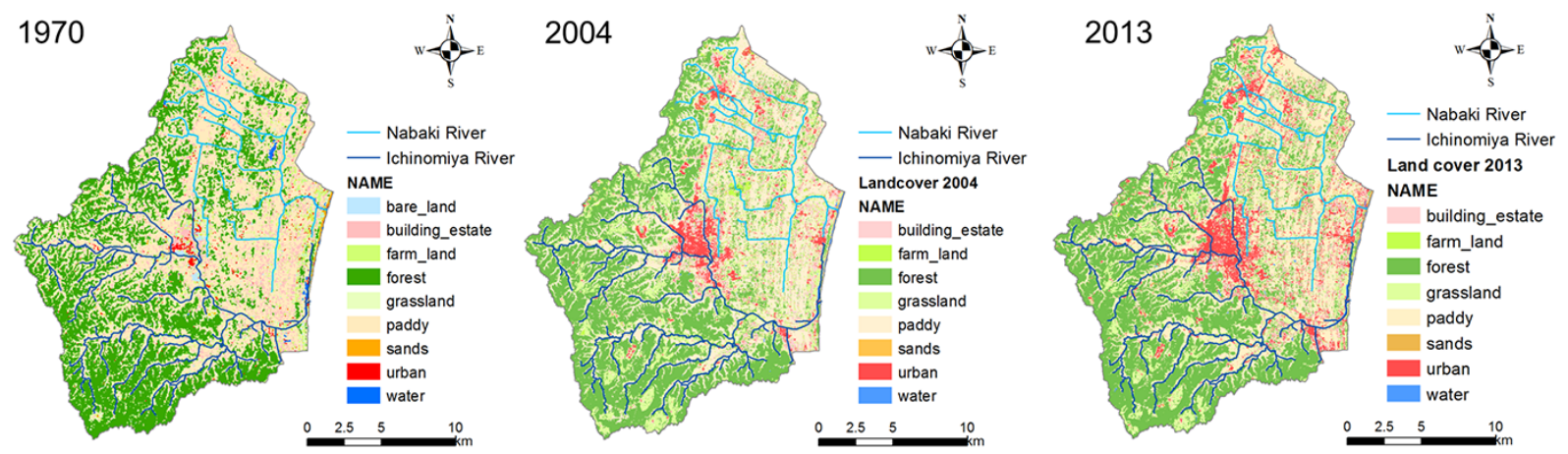

Figure 5. Land cover changes in 1970, 2004, and 2013. Land cover derived from Landsat-MSS and TM was classified by methods of maximum likelihood.

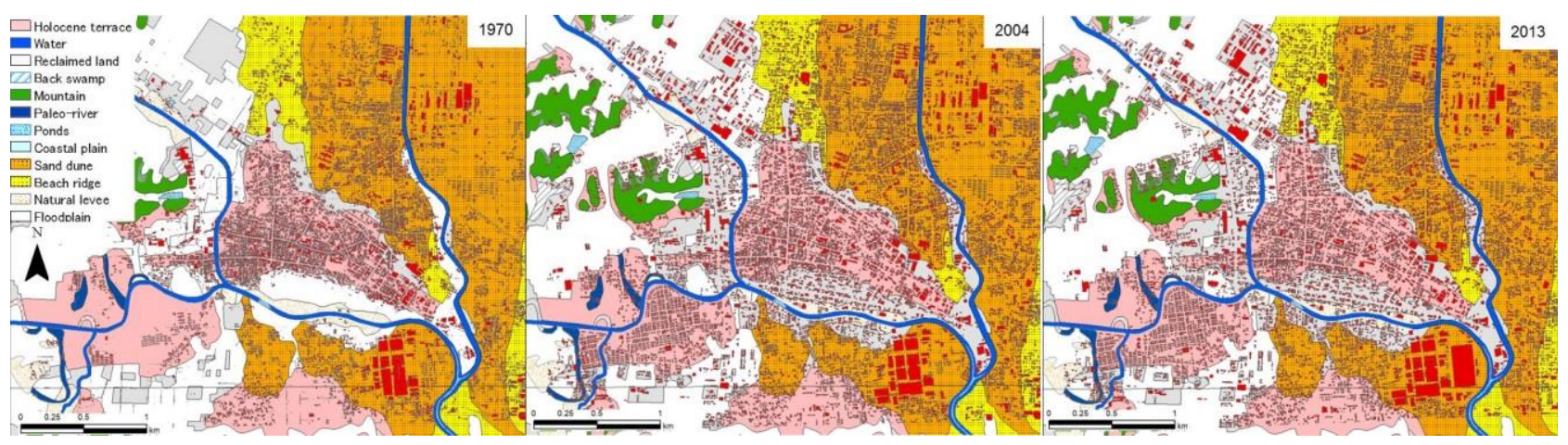

Figure 6. Expansion of the built-up area and geomorphological classification map in the central Mobara City. Red features indicate the building. 
plains and paleo-channels. Majority of the flood plains in the central Mobara City was also changed to reclaimed lands since 1970 by land development. The buildings were located on the relatively less vulnerable land and ground conditions in 1970, as a result of urban development and the expansion to the flood plains and paleo-channels since 1970, the one might be changed to be prone to floods.

\section{Summary}

The visible change of the spatial distribution of hazard potential areas with land subsidence were not clearly recognized whereas the influence of artificial land modification and the natural geomorphological condition are considered to be the factors that explain the spatial distribution and the temporal changes of the vulnerable areas to floods. Back swamp and flood plains are surrounded by beach ridges in the center of the Mobara City and its surrounding area; its geomorphological condition suggests that water tends to accumulate in the area. Honno area could be flood even with a light rainfall because of the back swamp area surrounded by the sand bars. Urbanizations have expanded the urban area into lowlands such as flood plains since 1970, and the function to control the floods might be reduced in the area because flood plains were changed to the reclaimed land.

It is important to consider natural factors such as changes of the rainfall patterns and geomorphological factor, artificial factors such as urbanization, as well as the influence of the land subsidence all together to discuss the spatial distribution of the flood-prone area in its temporal changes.

Acknowledgements. We would like to express our sincere gratitude to the Keiyo Natural Gas Association for supporting this study. Residential maps provided by ZENRIN CO., LTD are used as the CSIS Joint Research (No. 524) using spatial data provided by Spatial Information Science, The University of Tokyo.

\section{References}

Chiba prefecture: Report of Chiba prefecture flooding, 1971 (in Japanese).

Chiba prefecture: Report of Chiba prefecture flooding, 2005 (in Japanese).

Chiba Prefecture: Report of current state of land subsidence in Chiba prefecture, 2014 (in Japanese).

Chiba Prefecture: Documents of Ichinomiya River watershed meeting, 2015 (in Japanese).

Chen, H. L., Ito, Y., Sawamukai, M., and Tokunaga, T.: Flood hazard assessment in the Kujukuri Plain of Chiba Prefecture, Japan, based on GIS and multicriteria decision analysis, Nat. Hazards, 78, 105-120, doi:10.1007/s11069-015-1699-5, 2015.

Fitzpatrick, F. A., Knox, J. C., and Whitman, H. E.: Effects of historical land-cover changes on flooding and sedimentation, North Fish Creek, Wisconsin, USGS Water-resources investigations report, 99-4083, 1-12, 1999.

Galloway, D., Jones, D. R., and Ingebritsen, S. E.: Land subsidence in the United States, U.S. Geological survey circular 1182, USA, 1999.

Moriwaki, H.: The landform evolution of the Kujukuri Coastal Plain, Central Japan, Quaternary Res., 18, 1-16, 1979 (in Japanese).

Ng, A. h.-M., Ge, L., and Li, X.: Assessments of land subsidence in the Gippsland Basin of Australia using ALOS PALSAR data, Remote Sens. Environ., 159, 86-101, 2015.

Umitsu, M.: Alluvial lowlands and floods, Geo-environment of alluvial and coastal lowlands, Kokon-Shoin Publishers, Tokyo, 4748, 2012 (in Japanese). 